A. C. Calkin - M. E. Cooper •

K. A. Jandeleit-Dahm • T. J. Allen

\title{
Gemfibrozil decreases atherosclerosis in experimental diabetes in association with a reduction in oxidative stress and inflammation
}

Received: 27 June 2005 / Accepted: 19 October 2005 / Published online: 4 February 2006

C) Springer-Verlag 2006

\begin{abstract}
Aims/hypothesis: It is postulated that peroxisome proliferator-activated receptor $\alpha$ agonists confer cardiovascular benefits in diabetes, independently of their effects on lipid metabolism. We investigated putative mechanisms responsible for these anti-atherogenic effects in an in vivo model of diabetes-associated atherosclerosis. Materials and methods: Control and streptozotocin-induced diabetic apolipoprotein-deficient mice received gemfibrozil $\left(100 \mathrm{mg} \mathrm{kg}^{-1} \mathrm{day}^{-1}\right.$ ) or no treatment for 20 weeks. Aortic plaque deposition was assessed by Sudan IV staining and subsequent en face quantification. Superoxide production was measured using lucigenin-enhanced chemiluminescence. Markers of pathways including inflammation and oxidative stress were measured using real-time RT-PCR. Results: No significant effect of gemfibrozil was observed on glycated haemoglobin, cholesterol or insulin in diabetic mice. Diabetes was associated with a three-fold increase in plaque area and a significant increase in NADPH-dependent superoxide compared with control mice. Gemfibrozil significantly attenuated plaque area and superoxide production in diabetic mice. In addition, gemfibrozil reduced the expression of the genes encoding the NADPH oxidase subunits p47phox, gp91phox and Rac-1. In addition, gemfibrozil
\end{abstract}

Electronic Supplementary Material Supplementary material is available for this article at http://dx.doi.org/10.1007/s00125005-0102-6

A. C. Calkin $(\bowtie) \cdot$ M. E. Cooper

K. A. Jandeleit-Dahm · T. J. Allen

Diabetes Complications Laboratory,

Baker Heart Research Institute,

P.O. Box 6492, St Kilda Rd Central,

Melbourne 8008, Australia

e-mail: anna.calkin@baker.edu.au

Tel.: +613-8532-1465

Fax: $+613-8532-1288$

A. C. Calkin

Department of Medicine, Monash University,

Alfred Hospital,

Melbourne, Australia reduced the expression of the genes encoding nuclear factor kappa B (NF-kB) subunit, p65, the NF-kB-dependent chemokine monocyte chemoattractant protein-1, and tissue factor. Conclusions/interpretations: This study demonstrates that gemfibrozil exerts anti-atherogenic actions, independently of changes in cholesterol and glucose metabolism. Such findings emphasise the possible usefulness of fibrates such as gemfibrozil in a setting of atherosclerosis even in the absence of dyslipidaemia.

Keywords ApoE-/-mouse $\cdot$ Atherosclerosis Inflammation · Lipids $\cdot \mathrm{NAD}(\mathrm{P}) \mathrm{H}$ oxidase

Abbreviations AGII: angiotensin II $\cdot$ ApoE-/-: apolipoprotein-E-deficient - AGTR1: angiotensin II receptor subtype 1 - GHb: glycated haemoglobin $\cdot \mathrm{MCP}-1$ : monocyte chemoattractant protein-1 - MMP: matrix metalloproteinase $\cdot$ NF- $\mathrm{kB}$ : nuclear factor kappa B · PPAR: peroxisome proliferator-activated receptor - AGER: advanced glycation end product-specific receptor .

ROS: reactive oxygen species

\section{Introduction}

Fibrates are peroxisome proliferator-activated receptor (PPAR) $\alpha$ agonists primarily used for the treatment of dyslipidaemia. These agents regulate lipid metabolism by reducing triglycerides and increasing HDL cholesterol as well as by modulating LDL cholesterol, shifting the balance towards large buoyant, less-atherogenic particles $[1,2]$. More recently it has been postulated that fibrates exert antiatherogenic actions independently of their effects on lipid metabolism. This is supported by studies demonstrating PPAR $\alpha$ expression in cells of the vessel wall, including endothelial cells [3], smooth muscle cells [4] and macrophages [5]. Furthermore, in vitro studies have demonstrated that fibrates reduce a variety of mediators implicated in atherosclerotic plaque development, including proteins involved in cell recruitment [6], cell adhesion [7], cell migration [8], foam cell formation [9] and plaque stability 
[10]. In addition, polymorphisms in the PPAR $\alpha$ gene have been linked to alterations in the risk of cardiovascular disease in the absence of changes in lipid levels [11].

Large clinical trials investigating the effect of fibrates on cardiovascular disease in both diabetic and non-diabetic populations have demonstrated reductions in cardiovascular risk factors and events [2, 12-14]. However, these benefits were noted in the presence of changes in triglyceride and cholesterol levels. Both low HDL and increased LDL concentrations have independently been associated with increased cardiovascular risk [15]. Furthermore, there is a vast array of evidence to support a proatherogenic role for LDL, particularly oxidised LDL [16] and an anti-atherogenic role for HDL [17, 18]. Thus, improvements in the lipid profile per se would be anticipated to lead to a reduction in cardiovascular risk. Therefore, it remains to be determined whether fibrates exert direct anti-atherogenic effects, independently of their effects on lipid metabolism in vivo.

People with diabetes commonly have a lipid profile high in triglycerides and low in HDL cholesterol. In addition, they often have high levels of modified LDL (oxidised or glycated) [19]. Furthermore, diabetes is associated with an upregulation of the renin-angiotensin system [20], advanced glycation endproducts [21] and oxidative stress [22], all of which have been shown to contribute towards the development and progression of atherosclerosis. Thus, agents that not only improve the lipid profile but which may also independently reduce atherosclerosis are of great promise in diabetes. Indeed, such agents may be vasoprotective in a setting of atherosclerosis, even in the absence of significant dyslipidaemia.

The apolipoprotein-E-deficient (apoE-/-) mouse is a commonly used rodent model of atherosclerosis. The induction of diabetes results in a model of hyperglycaemia and hyperlipidaemia, metabolic changes often seen in human diabetes. In this model, plaques exhibit foamy cells and a lipid-rich necrotic core [20], a pathology similar to that seen in humans. This model has been used to assess the role of the renin-angiotensin system [20,23], the advanced glycation pathway [24] and growth factors [25] on diabetes-associated atherosclerosis. In these studies minimal effects on the lipid profile were observed, making this an ideal model to assess the role of the fibrate, gemfibrozil, on atherosclerosis in the absence of large alterations in lipid profile.

Thus, the aim of this study was to examine the potential anti-atherosclerotic effects of gemfibrozil in the streptozotocin-diabetic apoE-/- mouse, an in vivo model of diabetes-associated atherosclerosis where the effects of these agents on lipids are minimised.

\section{Materials and methods}

Animals

Six-week-old apoE-/-mice (backcrossed 20 times to a C57BL/6 background; Animal Resource Centre, Canning- vale, WA, Australia) were housed at the Precinct Animal Centre at AMREP, Melbourne, Australia and studied in accordance with the National Health and Medical Research Council and Alfred Hospital/Baker Heart Research Institute Animal Ethics guidelines. Mice were randomised to the following groups: control, receiving citrate buffer alone, and rendered diabetic by i.p. injection of streptozotocin $(55 \mathrm{mg}$ $\mathrm{kg}^{-1}$ day $^{-1}$ ) for 5 days [23]. Control and diabetic mice were then randomised to treatment with gemfibrozil $\left(100 \mathrm{mg} \mathrm{kg}^{-1}\right.$ day $^{-1}$ ) by gavage or no treatment for 20 weeks ( $n=22 /$ group). Mice had free access to standard chow and water. Mice were killed by i.p. injection of Euthal $(10 \mathrm{mg} / \mathrm{kg}$ ) (Delvet, Seven Hills, Australia) and subsequent exsanguination by cardiac puncture. Excised aortae were cleaned of excess fat and placed in neutral buffered formalin for analysis of the en face plaque area, then embedded in paraffin $(n=8)$, snap frozen in liquid nitrogen and stored at $-80^{\circ} \mathrm{C}$ for subsequent RNA extraction $(n=8)$ or used fresh to quantify vascular superoxide production $(n=6)$.

\section{Metabolic parameters}

Fasting glucose, cholesterol and triglycerides were measured using an automated system (Abbott Architecture ci8200; Abbott Laboratories, Abbott Park, IL, USA). Fasting insulin was measured by an RIA kit (Linco Research, St Charles, MI, USA; intra- and intervariability [CV] were 4.8 and $7.4 \%$, respectively). Glycated haemoglobin (GHb) was measured by HPLC [26].

\section{Plaque area quantification}

Plaque area was quantified as described previously [20]. Briefly, excised aortae were cleaned of adventitial fat and then stained with Sudan IV $(0.5 \%$ w/v) (Gurr, BDH, Poole, UK). The aortae were cut longitudinally and then divided into arch, thoracic and abdominal aorta. After pinning onto wax, aortae were photographed using an Axiocam camera (Zeiss, Heidelberg, Germany). Total and segmental plaque areas were quantified as percentage area visualised red as stained by Sudan IV. Tissue was then embedded in paraffin blocks and $4-\mu \mathrm{m}$ sections cut for subsequent immunohistochemical analysis.

\section{Vascular superoxide production}

Vascular superoxide production was measured by lucigenin-enhanced chemiluminescence as established by Omar et al. [27]. Freshly excised aortae were cleaned of adventitial fat, cut into 2-mm sections and placed in a 96-well plate. The origin of the aorta (arch, thoracic or abdominal) was randomised. NADPH $(125 \mu \mathrm{mol} / \mathrm{l})$ was added to wells in the presence of rotenone $(100 \mu \mathrm{mol} / \mathrm{l})$, a mitochondrial complex I inhibitor (Sigma-Aldrich, St Louis, MO, USA). Lucigenin (Sigma-Aldrich) was added to a final concen- 
Table 1 Metabolic parameters at conclusion of the study

\begin{tabular}{|c|c|c|c|c|}
\hline Parameter & Control & $\mathrm{C}+\mathrm{G}$ & Diabetic & $\mathrm{D}+\mathrm{G}$ \\
\hline Body weight (g) & $30.8 \pm 0.4$ & $28.3 \pm 0.4^{*}$ & $22.8 \pm 0.5^{*}$ & $23.1 \pm 0.5$ \\
\hline Glucose (mmol/1) & $12.6 \pm 1.7$ & $10.1 \pm 0.9$ & $32.6 \pm 1.2^{*}$ & $35.5 \pm 1.7$ \\
\hline $\mathrm{GHb}(\%)$ & $4.8 \pm 0.1$ & $3.4 \pm 0.1^{*}$ & $16.7 \pm 0.4^{*}$ & $15.7 \pm 0.7$ \\
\hline Insulin (ng/ml) & $0.47 \pm 0.07$ & $0.19 \pm 0.05^{*}$ & $0.20 \pm 0.05^{*}$ & $0.14 \pm 0.03$ \\
\hline Triglycerides (mmol/1) & $1.4 \pm 0.3$ & $1.0 \pm 0.1$ & $2.8 \pm 0.2 *$ & $3.4 \pm 0.7$ \\
\hline Total cholesterol (mmol/l) & $11.8 \pm 1.0$ & $7.6 \pm 1.2$ & $19.4 \pm 1.9^{*}$ & $19.8 \pm 1.8$ \\
\hline LDL cholesterol (mmol/1) & $7.9 \pm 0.7$ & $4.6 \pm 1.1^{*}$ & $16.1 \pm 0.9^{*}$ & $14.8 \pm 1.5$ \\
\hline HDL cholesterol (mmol/l) & $2.7 \pm 0.2$ & $2.6 \pm 0.2$ & $3.8 \pm 0.3$ & $3.5 \pm 0.5$ \\
\hline
\end{tabular}

Data are expressed as means \pm SEM. $n=21-22$ /group for body weight; $n=8$ /group for all other parameters $* p<0.05$ compared with control mice

$C+G$ control+gemfibrozil; $D+G$ diabetic + gemfibrozil

tration of $3.75 \mu \mathrm{mol} / \mathrm{l}$. Luminescence readings were taken every 6 min for $1 \mathrm{~h}$ and results averaged per well. Data were expressed as relative light units per $10 \mathrm{mg}$ tissue.

\section{Real-time RT-PCR}

As described previously [20], RNA was extracted from whole aortae by homogenisation using the Trizol method (Life Technologies, Rockville, MD, USA). RNA was subsequently treated with DNase (DNA Removal Kit; Ambion, Austin, TX, USA) and then the cDNA was reverse transcribed (Pierce, Rockford, IL, USA). Quantitative realtime RT-PCR was carried out using the Taqman system as previously described [20] on an ABI Prism 7700 Sequence Detector (Applied Biosystems, Foster City, CA, USA). Gene expression was normalised to $18 \mathrm{~S}$ mRNA. Probes and primers were designed in Primer Express (v1.3) (see Table $\mathrm{S} 1)$.

\section{Immunostaining}

Sections were stained with haematoxylin and eosin to assess plaque complexity using a standard protocol. Serial sections were stained with the macrophage marker F4/80 (Serotec, Oxford, UK) as previously described [28].

\section{Statistical analysis}

Data were analysed by ANOVA using Statview (v5.0). Fisher's test of least significant difference was used for post hoc analysis. Significance was defined as $p<0.05$. Results are represented as means \pm SEM unless otherwise specified.
Fig. 1 Plaque area as quantified by the en face approach. a Total plaque area; b aortic arch; c thoracic aorta; d abdominal aorta. $C$ control; $D$ diabetic; $C+G$ control + gemfibrozil; $D+G$ diabetic + gemfibrozil. $* p<0.05$ $* * p<0.01 * * * p<0.001$ vs $\mathrm{C}$; $\dagger p<0.01 \dagger \dagger p<0.001$ vs D $a$
$\frac{\pi}{0}$
$\frac{1}{0}$
$\frac{0}{2}$
$\frac{\pi}{0}$
$\frac{0}{0}$

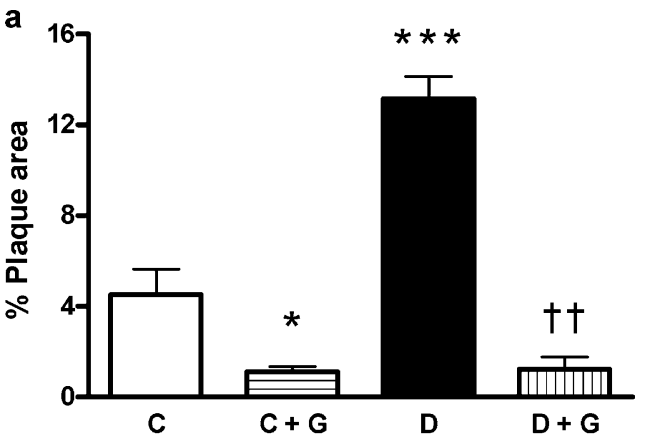

C

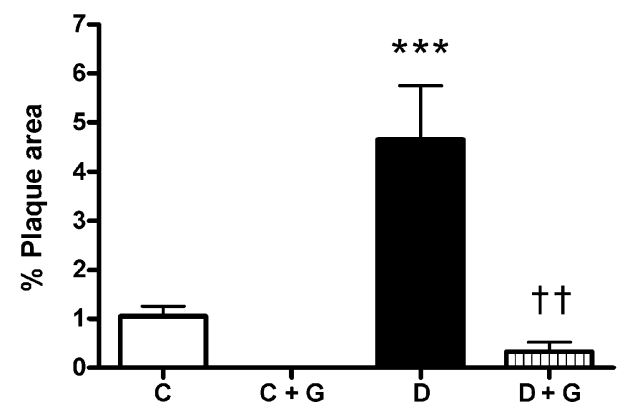

b

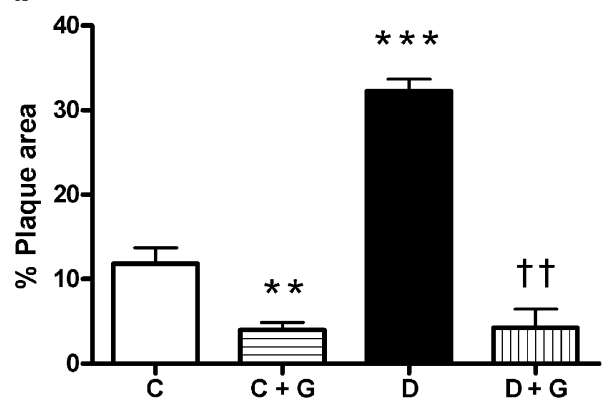

d

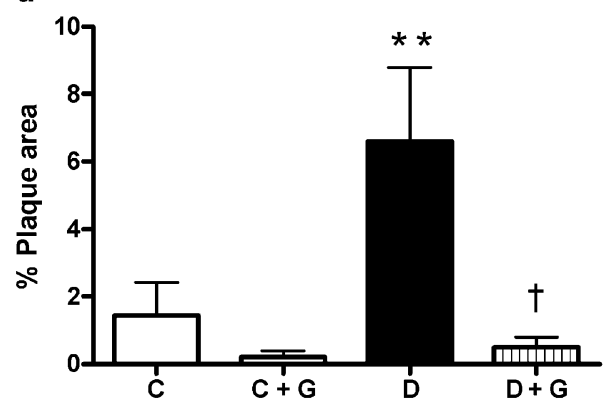


Fig. 2 Representative sections stained with haematoxylin and eosin demonstrating plaque complexity for control (a), control+gemfibrozil (b), diabetic (c) and diabetic+gemfibrozil (d) mice. Magnification $\times 850$
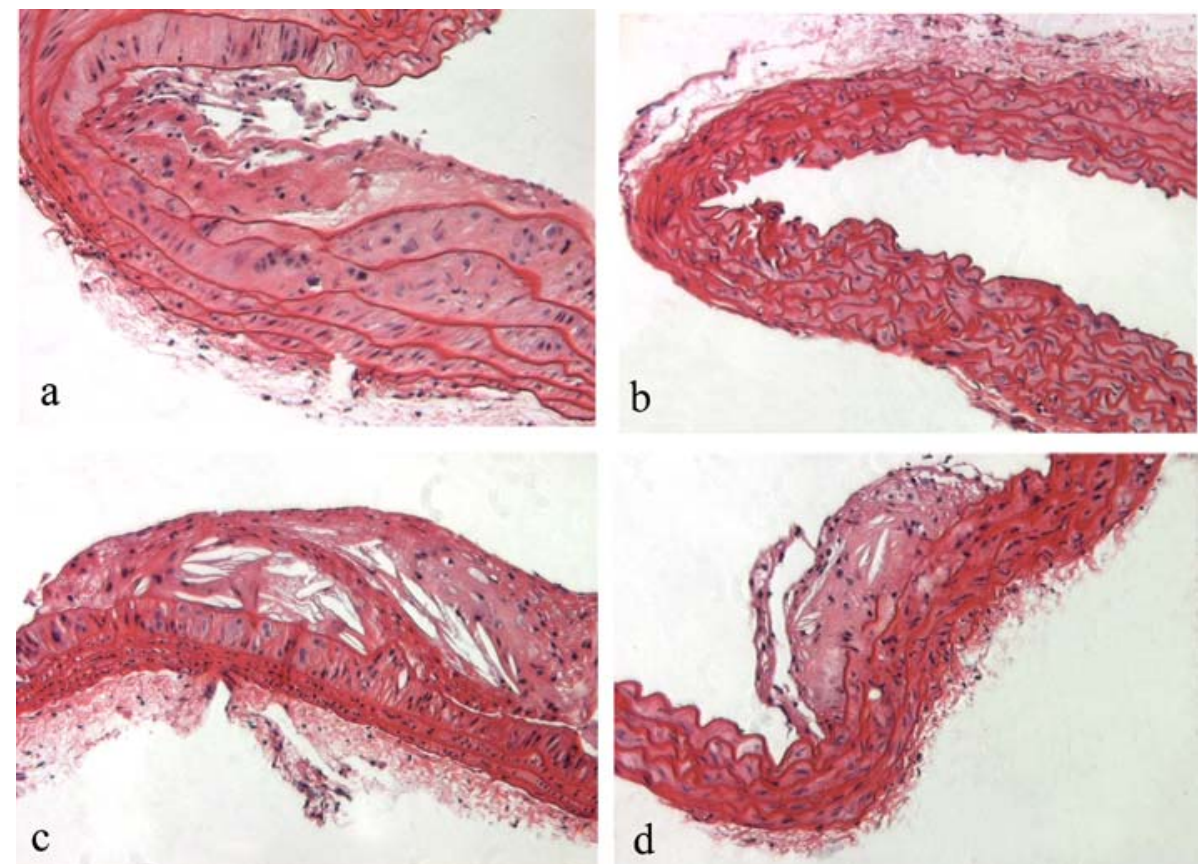

\section{Results}

Metabolic parameters

Diabetic mice had increased plasma glucose and GHb and decreased plasma insulin concentrations compared with control mice. Gemfibrozil did not affect these parameters in the streptozotocin-diabetic mice (Table 1). Diabetes was also associated with significant increases in triglycerides, total cholesterol and LDL cholesterol (Table 1). Gemfibrozil did not significantly alter lipid levels in diabetic mice. In control mice gemfibrozil significantly reduced $\mathrm{GHb}$ and insulin levels and LDL cholesterol. There was no difference in HDL cholesterol among all four groups (Table 1).
Plaque area quantification

Diabetes was associated with an approximately three-fold increase in plaque area compared with control mice $(p<0.001$; Fig. 1a). Subsequent analysis of plaque localisation revealed a significant increase in arch, thoracic and abdominal plaque deposition in diabetic mice (Fig. 1b-d). Gemfibrozil treatment was associated with an attenuation of plaque deposition at all three sites within the aortae in diabetic mice. By contrast, gemfibrozil only attenuated plaque deposition significantly in the aortic arch of control mice. Figure $2 \mathrm{a}-\mathrm{d}$ shows representative pictures of plaque complexity in the absence and presence of gemfibrozil treatment. Cross-sectional analysis revealed that diabetic
Fig. 3 a Superoxide production ( $R L U$ relative light units) as assessed by lucigenin-enhanced chemiluminescence. Expression of $\mathbf{b} \mathrm{NAD}(\mathrm{P}) \mathrm{H}$ oxidase subunits gp91phox, c p47phox and $\mathbf{d}$ Rac-1 as quantified by real-time RT-PCR. $C$ control; $D$ diabetic; $C+G$ control+ gemfibrozil; $D+G$ diabetic+ gemfibrozil. $* p<0.05, * * p<0.01$, $* * * p<0.001$ vs $\mathrm{C} ; \dagger p<0.05$ vs D a
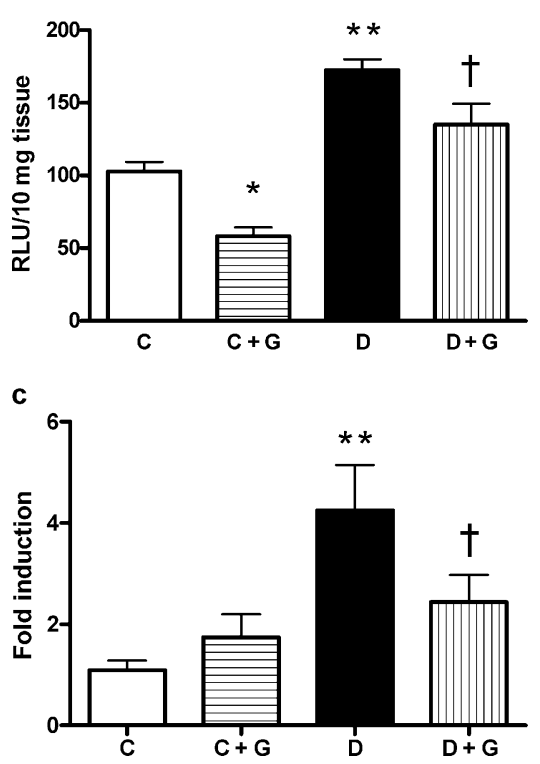

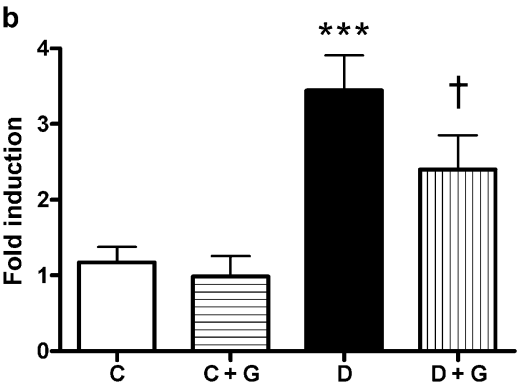

d

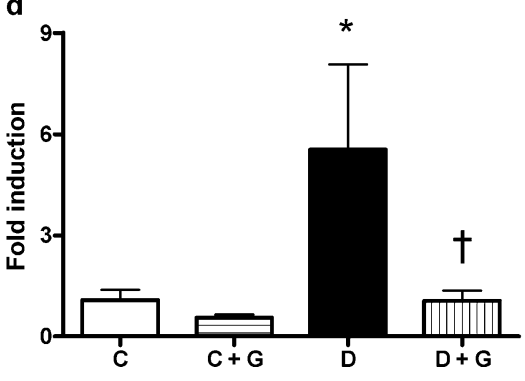


Table 2 Gene expression (arbitrary units) of markers and mediators of atherosclerosis at conclusion of the study

\begin{tabular}{lllll}
\hline Parameter & Control & $\mathrm{C}+\mathrm{G}$ & Diabetic & $\mathrm{D}+\mathrm{G}$ \\
\hline Agtr1 & $1.2 \pm 0.2$ & $0.4 \pm 0.1^{*}$ & $1.4 \pm 0.2$ & $0.6 \pm 0.1 \dagger$ \\
Ccl2 & $1.2 \pm 0.2$ & $1.2 \pm 0.3$ & $6.0 \pm 0.8^{*}$ & $3.2 \pm 0.4 \dagger$ \\
Mmp2 & $1.1 \pm 0.1$ & $0.5 \pm 0.1$ & $1.8 \pm 0.2^{*}$ & $1.2 \pm 0.2 \dagger$ \\
Mmp9 & $1.1 \pm 0.2$ & $1.2 \pm 0.4$ & $1.4 \pm 0.2$ & $0.6 \pm 0.1 \dagger$ \\
Rela & $1.1 \pm 0.2$ & $0.8 \pm 0.3$ & $3.3 \pm 1.0^{*}$ & $0.6 \pm 0.2 \dagger$ \\
Ager & $0.9 \pm 0.2$ & $0.8 \pm 0.3$ & $2.9 \pm 0.7^{*}$ & $1.2 \pm 0.3 \dagger$ \\
F3 & $1.0 \pm 0.1$ & $0.6 \pm 0.2$ & $4.1 \pm 1.1^{*}$ & $1.4 \pm 0.4 \dagger$ \\
Vcam1 & $1.4 \pm 0.4$ & $0.9 \pm 0.3$ & $3.0 \pm 0.7^{*}$ & $3.3 \pm 0.9$ \\
\hline
\end{tabular}

Data are expressed as means \pm SEM. $n=7-8$ /group

$* p<0.05$ compared with control mice

$\dagger p<0.05$ compared with diabetic mice

$C+G$ control + gemfibrozil; $D+G$ diabetic + gemfibrozil; $V C A M 1$

vascular cell adhesion molecule-1

mice had more complex, advanced lesions with a thickened intima and fibrous cap covering macrophages, smooth muscle cells and cholesterol clefts, as has been previously described by our group [20]. Gemfibrozil attenuated the presence and complexity of plaques in both control and diabetic mice, as seen in Fig. 2b,d.

\section{Oxidative stress}

NADPH-dependent superoxide production was increased in the aortae of diabetic mice (Fig. 3a; $p<0.01$ ). Gemfibrozil significantly abrogated superoxide production in both control and diabetic mice. To further investigate the mechanism underlying the observed reduction in vascular super- oxide production, we assessed the gene regulation of the various $\mathrm{NAD}(\mathrm{P}) \mathrm{H}$ oxidase subunits. We demonstrated that diabetes was associated with an upregulation of $C y b b$ (control vs diabetic, $p<0.001$ ), Ncfl (control vs diabetic, $p<0.01)$ and Racl $(p<0.05)$, the genes encoding gp91phox, p47phox and Rac-1, respectively. Gemfibrozil attenuated gene expression of each of these subunits in diabetic mice $(p<0.05$; Fig. 3b-d).

\section{Inflammation}

We measured the regulation of nuclear factor kappa B (NF-KB), a mediator of inflammation, via gene expression of the NF-kB subunit, Rela. Diabetes was associated with an upregulation of the expression of Rela and this was attenuated by gemfibrozil treatment (Table 2 ). We subsequently investigated the expression of the gene $(\mathrm{Ccl} 2)$ encoding the chemokine monocyte chemoattractant protein-1 (MCP-1), an NF- $\mathrm{kB}$-dependent protein which has been shown to play an important role in the initial stages of plaque development [29]. We demonstrated an upregulation of $\mathrm{Ccl}$ gene expression in the aortae of diabetic mice which was attenuated by gemfibrozil $(p<0.001)$. An increase in $C c l 2$ gene expression may indicate increased macrophage infiltration, and thus immunostaining for the macrophage marker F4/80 was undertaken [28]. Representative pictures of macrophage staining in the vessel wall (Fig. 4a-d) demonstrate localisation of macrophages to the intima and media, which appear to be more pronounced in the diabetic mice compared with all other groups, consistent with enhanced $\mathrm{Ccl} 2$ expression.

Tissue factor (F3) has also been demonstrated to be under the regulation of NF-kB [30]. Thus, we investigated

Fig. 4 Representative sections stained with the macrophage marker, F4/80 for control (a), control+gemfibrozil (b), diabetic (c) and diabetic+ gemfibrozil (d) mice. Magnification $\times 850$
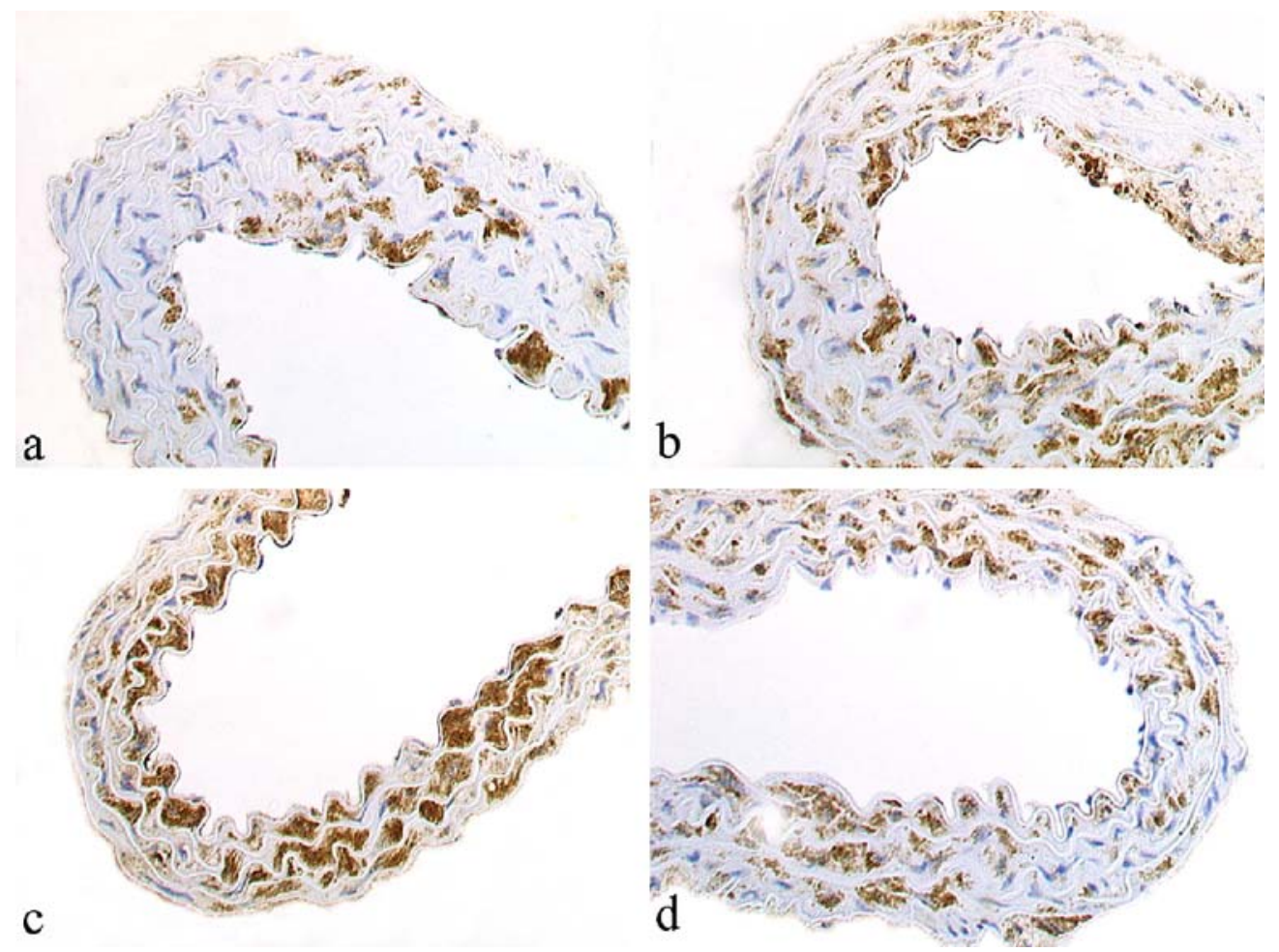
the effect of gemfibrozil on $F 3$ gene expression. Diabetes was indeed associated with a four-fold increase in F3 expression and this was abrogated by gemfibrozil treatment. Finally, we investigated the effect of fibrate therapy on expression of the adhesion molecule, vascular cell adhesion molecule. Whilst we observed a marked increase in Vcam 1 gene expression in diabetic mice, gemfibrozil did not affect this parameter.

\section{Renin-angiotensin system}

Angiotensin II (AGII) has been shown to exert effects on both inflammation and oxidative stress via the AGII receptor subtype $1[31,32]$. In the current study we demonstrated a reduction in Agtrl gene expression in the aortae of both control $(p<0.05)$ and diabetic mice $(p<0.05)$ with gemfibrozil treatment (Table 2).

Regulation of advanced glycation end-productspecific receptor

In diabetic mice, expression of Ager, the gene encoding the advanced glycation end product-specific receptor (AGER), was upregulated $(p<0.01)$ and this was abrogated by gemfibrozil treatment $(p<0.05)$ (Table 2).

\section{Markers of plaque stability}

Matrix metalloproteinases (MMPs) are involved in degradation of extracellular matrix and both MMP2 and MMP9 have been associated with plaque stability [33]. We demonstrated that diabetic mice had an upregulation in aortic gene expression of Mmp2 and this was attenuated with gemfibrozil treatment (Table 2). Furthermore, whilst diabetes was not associated with an alteration in $M m p 9$ gene expression, gemfibrozil significantly downregulated gene expression of this enzyme in diabetic mice $(p<0.05$; Table 2$)$.

\section{Discussion}

This study clearly demonstrated that gemfibrozil attenuates diabetes-associated atherosclerosis in the absence of readily detectable changes in lipid or glucose metabolism. By contrast, a range of other pathways that have been implicated in the development of atherosclerosis, in the presence or absence of diabetes, were influenced by gemfibrozil treatment. Indeed, in aortae from our diabetic mice, gemfibrozil treatment was associated with changes in: (1) various markers and mediators of inflammation; (2) oxidative stress; (3) AGER; (4) the renin-angiotensin system; and (5) MMPs implicated in plaque stability.

While a small number of studies have assessed the role of fibrates and PPAR $\alpha$ in rodents, albeit in a non-diabetic context, these studies reported conflicting findings. A study of high-fat-fed PPAR $\alpha-/-$ apoE-/-mice demonstrated lower en face atherosclerotic lesions compared with PPA $\mathrm{R} \alpha+/+$ apoE-/- mice [34]. Whether these effects were lipid independent could not be determined, since the genetic deletion of PPAR $\alpha$ was associated with higher VLDL levels. $\mathrm{Fu}$ et al. have reported that fibrate therapy in apoE-/mice increases fatty acid oxidation as expected. Somewhat surprisingly, they also observed an increase in plasma cholesterol level and subsequent plaque deposition [35]. In contrast, Duez et al. observed no increase in atherosclerosis in the aortic sinus of younger apoE $-/-$ mice in the presence of increased plasma cholesterol and triglyceride levels with fenofibrate treatment [36]. Furthermore, in older apoE- $-1-$ mice, in the absence of changes in plasma lipid levels, these authors demonstrated a reduction in aortic cholesterol content. The latter study, whilst difficult to interpret, does suggest direct effects of this fibrate on the vessel wall. Indeed, our findings clearly support a direct anti-atherogenic role of fibrates in the setting of diabetes. We also observed an attenuation of plaque deposition with gemfibrozil in control mice; however, this was in the presence of a reduction in LDL cholesterol and therefore cannot be attributed purely to a direct vascular effect.

The apparent independent effects of gemfibrozil demonstrated in the current study are supported by a number of small clinical studies examining the role of fibrates on endothelial function and inflammation. Playford et al. demonstrated an improvement in endothelial function, as assessed by flow-mediated dilation, which was negatively correlated with changes in lipid profile in patients with type 2 diabetes [37]. Okapcova and Gabor demonstrated reductions in soluble vascular cell and intercellular adhesion molecule-1 and soluble E-selectin, which were not correlated with lipid profile in the presence or absence of diabetes [38].

Diabetes is recognised as a proinflammatory state, as shown by increased levels of adhesion molecules, cytokines and chemokines which accelerate the development of atherosclerotic plaques [38]. NF- $\mathrm{KB}$ is a proinflammatory transcription factor which has been demonstrated to regulate various pro-atherogenic cytokines and growth factors. PPAR agonists are now thought to mediate many of their antiinflammatory actions via the transrepression pathway, interfering with the activation of NF- $\mathrm{KB}$ and activator protein-1 pathways [39]. We have confirmed that gemfibrozil treatment is associated with a reduction in Rela gene expression in vivo. This may be a direct effect or may be secondary to an attenuation in the aortic gene expression of Agtrl, as AGII has been reported to be associated with increased expression of the Rela subunit of NF-KB [32]. This effect on Rela expression appears to be biologically relevant since altered expression of the chemokine $C$ cl2, known to be under the regulation of NF- $\mathrm{kB}$ [40], was also observed. MCP-1 is a key atherogenic molecule responsible for migration of monocytes to the intima [29], and indeed we observed fewer macrophages in the vessel wall of gemfibroziltreated mice. Our findings confirm previous studies in endothelial cells which demonstrated a role for fibrates in 
the attenuation of MCP-1 expression [6] and suggest that this drug may also downregulate other NF- $\mathrm{kB}$-dependent pro-atherogenic molecules.

Diabetic mice demonstrated an upregulation of AGER, as has been shown previously [41]. We have demonstrated a novel finding, that gemfibrozil treatment was associated with an attenuation of Ager expression in diabetic mice. The effect of interference with AGER has clearly been demonstrated by Bucciarelli et al., who observed a marked reduction in atherosclerosis with soluble AGER treatment [24] in association with reductions in inflammation and mononuclear and smooth muscle cell activation. This finding is, however, not totally surprising since Ager expression is regulated by NF- $\mathrm{KB}$ with an NF-KB-binding site in its promoter region [42]. Interestingly, the converse is also true with $A G E R$ inducing NF-KB expression [43]. In the current study, we have demonstrated a reduction in expression of the genes encoding AGER and NF-KB and cannot at this stage determine which of these pathways is upstream and most closely linked to PPAR $\alpha$ agonism.

Tissue factor has also been shown to be under the regulation of NF- $\mathrm{KB}[30]$ and be upregulated in diabetes, a state of increased thrombosis associated with plaque rupture [24]. In the current study we observed an increase in F3 expression in the vessels of diabetic mice and have confirmed previous findings demonstrating the attenuation of F3 with fibrate treatment in endothelial cells [30], monocytes and macrophages [44].

MMPs play a role in extracellular matrix degradation. In the setting of atherosclerosis this can lead to degradation of the fibrous cap, promoting plaque rupture [45]. Both MMP2 and MMP9 are produced in atherosclerotic plaques and appear to localise around the shoulder region of the plaque [33]. In the current study diabetes was associated with an upregulation of $M m p 2$, but no change in $M m p 9$ expression. Gemfibrozil abrogated both $M m p 2$ and $M m p 9$ gene expression, implicating a further role for this drug in improving plaque stability.

Oxidative stress is well recognised to promote plaque formation via effects on cell adhesion, migration, proliferation, endothelial dysfunction and inflammation [46]. Superoxide, generated from NADPH oxidase, appears to be the most abundant form of reactive oxygen species (ROS) in the vessel wall, although other ROS formed include hydrogen peroxide, peroxynitrite and nitrotyrosine [46]. Superoxide production has been correlated with endothelial function and clinical risk factors of atherosclerosis [47]. Previous literature demonstrates conflicting effects on fibrates in the in vitro setting. Studies in macrophages demonstrate that $\operatorname{PPAR} \alpha$ activation leads to increased superoxide and hydrogen peroxide production via an upregulation of NADPH oxidase subunits, p47phox, p67phox and gp91phox [48]. Conversely, studies in endothelial cells demonstrated a decrease in p22phox and p47phox and increased antioxidant expression with fibrate therapy [49]. In the current study we observed an upregulation of superoxide production in the aortae of diabetic mice. Gemfibrozil significantly attenuated superoxide production in both control and diabetic mice Furthermore, gemfibrozil abrogated the diabetes-induced increase in gene expression of various NADPH oxidase subunits including p47phox, gp91phox and Rac-1. Our findings are consistent with those of Evans et al., who demonstrated a reduction in oxidative stress after 3 months of treatment with ciprofibrate in subjects with type 2 diabetes [50].

Gemfibrozil treatment also had effects on the reninangiotensin system with a reduction in Agtrl gene expression in diabetic mice. AGII influences a variety of pathways to induce pro-atherogenic effects. In the model of AGII infusion, albeit in a non-diabetic context, fibrates have been associated with reductions in inflammation and oxidative stress [51].

AGII is widely recognised to increase the production of ROS, and in particular, to enhance NADPH oxidase activity [52]. Furthermore, ROS can activate MMPs, in particular by activation of NADPH oxidase, and more specifically, the p47phox subunit of NADPH oxidase [53]. Interestingly, a recent study has demonstrated that AGII reduces MMP2 in a p47phox-dependent manner, although these studies were performed in cultured smooth muscle cells [31]. In the current study we observed a reduction in Agtrl, Ncfl and Mmp2 gene expression. We postulate that the observed reduction in AGTR1 expression in diabetic mice resulted in a downregulation of AGII-mediated effects, reducing $\mathrm{NAD}(\mathrm{P}) \mathrm{H}$ oxidase subunit expression, and thus ROS, and subsequently MMP expression.

In diabetic mice, gemfibrozil had no effect on glucose, $\mathrm{GHb}$ or insulin levels. In control mice, however, gemfibrozil treatment resulted in a reduction in $\mathrm{GHb}$ and insulin levels. Both animal $[54,55]$ and clinical studies [56] have reported an insulin-sensitising effect of fibrate therapy, which they attribute to a reduction in lipids. Moreover, Ide and co-workers demonstrated that fibrates can regulate the insulin receptor signalling pathway [57]. It is possible that in contrast to the control mice, gemfibrozil had no effect on glycaemic control in diabetic mice, since this is a state of insulin deficiency with less opportunity for the potential insulin-sensitising effects of the fibrate to be operative.

Thus, this study demonstrates clearly, in an in vivo model of diabetes-associated atherosclerosis, that gemfibrozil abrogates plaque development in the absence of significant changes in lipid and glucose metabolism. Moreover, this drug acts on a number of pathways to reduce inflammation and oxidative stress and potentially to improve plaque stability via effects on MMPs and F3. Whilst these findings expand our understanding of the independent vascular effects of fibrates, further studies are required to fully elucidate specific inflammatory and oxidative stress pathways by which gemfibrozil confers its anti-atherogenic effects. These might include clinical studies assessing the effect of fibrates on markers of inflammation and endothelial function after a short duration in which effects on lipids are not yet apparent. Furthermore, delayed interventional studies such as those by Bucciarelli et al. [24], which more closely resemble the clinical setting, will assist in determining the role of fibrates in the treatment of atherosclerosis. Finally, the increasingly recognised pleiotropic actions of fibrates may be highly relevant to their potential wider use in the clinic 
and in particular to the high-risk diabetic population with or without dyslipidaemia.

Acknowledgements A. C. Calkin is supported by a postgraduate scholarship from the National Heart Foundation. K. A. JandeleitDahm is a recipient of a National Heart Foundation Fellowship. T. J. Allen is an R. D. Wright Fellow of the National Health and Medical Research Council and Diabetes Australia. The authors would like to thank J. Pete, C. Tikellis, M. Arnstein, V. Thallas-Bonke, C. Smith and M. Lassila for their excellent technical assistance. We would also like to thank S. Miljavec, G. Langmaid and P. Aldersea for their expertise in animal handling. We acknowledge the gift of gemfibrozil compound from Pfizer Pty. Limited.

\section{References}

1. Staels B, Dallongeville J, Auwerx J, Schoonjans K, Leitersdorf E, Fruchart JC (1998) Mechanism of action of fibrates on lipid and lipoprotein metabolism. Circulation 19:2088-2093

2. Ruotolo G, Ericsson CG, Tettamanti C et al (1998) Treatment effects on serum lipoprotein lipids, apolipoproteins and low density lipoprotein particle size and relationships of lipoprotein variables to progression of coronary artery disease in the Bezafibrate Coronary Atherosclerosis Intervention Trial (BECAIT). J Am Coll Cardiol 6:1648-1656

3. Inoue I, Shino K, Noji S, Awata T, Katayama S (1998) Expression of peroxisome proliferator-activated receptor alpha (PPAR alpha) in primary cultures of human vascular endothelial cells. Biochem Biophys Res Commun 2:370-374

4. Staels B, Koenig W, Habib A et al (1998) Activation of human aortic smooth-muscle cells is inhibited by PPARalpha but not by PPARgamma activators. Nature 393:790-793

5. Chinetti G, Griglio S, Antonucci M et al (1998) Activation of proliferator-activated receptors alpha and gamma induces apoptosis of human monocyte-derived macrophages. J Biol Chem 40:25573-25580

6. Lee H, Shi W, Tontonoz P et al (2000) Role for peroxisome proliferator-activated receptor alpha in oxidized phospholipidinduced synthesis of monocyte chemotactic protein-1 and interleukin-8 by endothelial cells. Circ Res 6:516-521

7. Jackson SM, Parhami F, Xi XP et al (1999) Peroxisome proliferator-activated receptor activators target human endothelial cells to inhibit leukocyte-endothelial cell interaction. Arterioscler Thromb Vasc Biol 9:2094-2104

8. Shu H, Wong B, Zhou G et al (2000) Activation of PPARalpha or gamma reduces secretion of matrix metalloproteinase 9 but not interleukin 8 from human monocytic THP-1 cells. Biochem Biophys Res Commun 1:345-349

9. Chinetti G, Gbaguidi FG, Griglio S et al (2000) CLA-1/SR-BI is expressed in atherosclerotic lesion macrophages and regulated by activators of peroxisome proliferator-activated receptors. Circulation 20:2411-2417

10. Rival Y, Beneteau N, Chapuis V et al (2004) Cardiovascular drugs inhibit MMP-9 activity from human THP-1 macrophages. DNA Cell Biol 5:283-292

11. Flavell DM, Jamshidi Y, Hawe E et al (2002) Peroxisome proliferator-activated receptor alpha gene variants influence progression of coronary atherosclerosis and risk of coronary artery disease. Circulation 12:1440-1445

12. Rubins HB, Robins SJ, Collins D et al (1999) Gemfibrozil for the secondary prevention of coronary heart disease in men with low levels of high-density lipoprotein cholesterol. Veterans Affairs High-Density Lipoprotein Cholesterol Intervention Trial Study Group. N Engl J Med 6:410-418
13. Frick MH, Syvanne M, Nieminen MS et al (1997) Prevention of the angiographic progression of coronary and vein-graft atherosclerosis by gemfibrozil after coronary bypass surgery in men with low levels of HDL cholesterol. Lopid Coronary Angiography Trial (LOCAT) Study Group. Circulation 7:2137-2143

14. Anon (2001) Effect of fenofibrate on progression of coronaryartery disease in type 2 diabetes: the Diabetes Atherosclerosis Intervention Study, a randomised study. Lancet 357:905-910

15. Turner RC, Millns H, Neil HA et al (1998) Risk factors for coronary artery disease in non-insulin dependent diabetes mellitus: United Kingdom Prospective Diabetes Study (UKPDS: 23). BMJ 316:823-828

16. Hulthe J, Fagerberg B (2002) Circulating oxidized LDL is associated with subclinical atherosclerosis development and inflammatory cytokines (AIR Study). Arterioscler Thromb Vasc Biol 7:1162-1167

17. Cockerill GW, Huehns TY, Weerasinghe A et al (2001) Elevation of plasma high-density lipoprotein concentration reduces interleukin-1-induced expression of E-selectin in an in vivo model of acute inflammation. Circulation 1:108-112

18. Ashby DT, Rye KA, Clay MA, Vadas MA, Gamble JR, Barter PJ (1998) Factors influencing the ability of HDL to inhibit expression of vascular cell adhesion molecule-1 in endothelial cells. Arterioscler Thromb Vasc Biol 9:1450-1455

19. Guerin M, Le Goff W, Lassel TS, Van Tol A, Steiner G, Chapman MJ (2001) Atherogenic role of elevated CE transfer from HDL to VLDL(1) and dense LDL in type 2 diabetes: impact of the degree of triglyceridemia. Arterioscler Thromb Vasc Biol 2:282-288

20. Candido R, Jandeleit-Dahm KA, Cao Z et al (2002) Prevention of accelerated atherosclerosis by angiotensin-converting enzyme inhibition in diabetic apolipoprotein E-deficient mice. Circulation 2:246-253

21. Kilhovd BK, Berg TJ, Birkeland KI, Thorsby P, Hanssen KF (1999) Serum levels of advanced glycation end products are increased in patients with type 2 diabetes and coronary heart disease. Diabetes Care 9:1543-1548

22. Giugliano D, Ceriello A, Paolisso G (1996) Oxidative stress and diabetic vascular complications. Diabetes Care 3:257-267

23. Candido R, Allen TJ, Lassila M et al (2004) Irbesartan but not amlodipine suppresses diabetes-associated atherosclerosis. Circulation 12:1536-1542

24. Bucciarelli LG, Wendt T, Qu W et al (2002) RAGE blockade stabilizes established atherosclerosis in diabetic apolipoprotein E-null mice. Circulation 22:2827-2835

25. Lassila M, Allen TJ, Cao Z et al (2004) Imatinib attenuates diabetes-associated atherosclerosis. Arterioscler Thromb Vasc Biol 5:935-942

26. Cefalu WT, Wang ZQ, Bell-Farrow A, Kiger FD, Izlar C (1994) Glycohemoglobin measured by automated affinity HPLC correlates with both short-term and long-term antecedent glycemia. Clin Chem 7:1317-1321

27. Omar HA, Cherry PD, Mortelliti MP, Burke-Wolin T, Wolin MS (1991) Inhibition of coronary artery superoxide dismutase attenuates endothelium-dependent and -independent nitrovasodilator relaxation. Circ Res 3:601-608

28. Calkin AC, Forbes JM, Smith CM et al (2005) Rosiglitazone attenuates atherosclerosis in a model of insulin insufficiency independent of its metabolic effects. Arterioscler Thromb Vasc Biol 25:1903-1909

29. Aiello RJ, Bourassa PA, Lindsey S et al (1999) Monocyte chemoattractant protein-1 accelerates atherosclerosis in apolipoprotein E-deficient mice. Arterioscler Thromb Vasc Biol 6:1518-1525

30. Kaneko T, Fujii S, Matsumoto A et al (2003) Induction of tissue factor expression in endothelial cells by basic fibroblast growth factor and its modulation by fenofibric acid. Thromb J 1:6 
31. Luchtefeld M, Grote K, Grothusen C et al (2005) Angiotensin II induces MMP-2 in a p47phox-dependent manner. Biochem Biophys Res Commun 1:183-188

32. Tham DM, Martin-McNulty B, Wang YX et al (2002) Angiotensin II is associated with activation of NF-kappaB-mediated genes and downregulation of PPARs. Physiol Genomics 1:21-30

33. Galis ZS, Sukhova GK, Lark MW, Libby P (1994) Increased expression of matrix metalloproteinases and matrix degrading activity in vulnerable regions of human atherosclerotic plaques. $\mathrm{J}$ Clin Invest 6:2493-2503

34. Tordjman K, Bernal-Mizrachi C, Zemany L et al (2001) PPARalpha deficiency reduces insulin resistance and atherosclerosis in apoE-null mice. J Clin Invest 8:1025-1034

35. Fu T, Kashireddy P, Borensztajn J (2003) The peroxisomeproliferator-activated receptor alpha agonist ciprofibrate severely aggravates hypercholesterolaemia and accelerates the development of atherosclerosis in mice lacking apolipoprotein E. Biochem J 373:941-947

36. Duez H, Chao YS, Hernandez M et al (2002) Reduction of atherosclerosis by the peroxisome proliferator-activated receptor alpha agonist fenofibrate in mice. J Biol Chem 50:48051-48057

37. Playford DA, Watts GF, Best JD, Burke V (2002) Effect of fenofibrate on brachial artery flow-mediated dilatation in type 2 diabetes mellitus. Am J Cardiol 11:1254-1257

38. Okapcova J, Gabor D (2004) The levels of soluble adhesion molecules in diabetic and nondiabetic patients with combined hyperlipoproteinemia and the effect of ciprofibrate therapy. Angiology 6:629-639

39. Delerive P, De Bosscher K, Besnard S et al (1999) Peroxisome proliferator-activated receptor alpha negatively regulates the vascular inflammatory gene response by negative cross-talk with transcription factors NF-kappaB and AP-1. J Biol Chem 45:32048-32054

40. Dwarakanath RS, Sahar S, Reddy MA, Castanotto D, Rossi JJ, Natarajan R (2004) Regulation of monocyte chemoattractant protein-1 by the oxidized lipid, 13-hydroperoxyoctadecadienoic acid, in vascular smooth muscle cells via nuclear factor-kappa B (NF-kappa B). J Mol Cell Cardiol 4:585-595

41. Kislinger T, Tanji N, Wendt $T$ et al (2001) Receptor for advanced glycation end products mediates inflammation and enhanced expression of tissue factor in vasculature of diabetic apolipoprotein E-null mice. Arterioscler Thromb Vasc Biol 6:905-910

42. Li J, Schmidt AM (1997) Characterization and functional analysis of the promoter of RAGE, the receptor for advanced glycation end products. J Biol Chem 26:16498-16506

43. Bierhaus A, Schiekofer S, Schwaninger M et al (2001) Diabetes-associated sustained activation of the transcription factor nuclear factor-kappaB. Diabetes 12:2792-2808

44. Neve BP, Corseaux D, Chinetti G et al (2001) PPARalpha agonists inhibit tissue factor expression in human monocytes and macrophages. Circulation 2:207-212
45. Aikawa M, Rabkin E, Okada Y et al (1998) Lipid lowering by diet reduces matrix metalloproteinase activity and increases collagen content of rabbit atheroma: a potential mechanism of lesion stabilization. Circulation 24:2433-2444

46. Griendling KK, Sorescu D, Ushio-Fukai M (2000) NAD(P)H oxidase: role in cardiovascular biology and disease. Circ Res 5:494-501

47. Guzik TJ, West NE, Black E et al (2000) Vascular superoxide production by $\mathrm{NAD}(\mathrm{P}) \mathrm{H}$ oxidase: association with endothelial dysfunction and clinical risk factors. Circ Res 9:E85-E90

48. Teissier E, Nohara A, Chinetti G et al (2004) Peroxisome proliferator-activated receptor alpha induces NADPH oxidase activity in macrophages, leading to the generation of LDL with PPAR-alpha activation properties. Circ Res 12:1174-1182

49. Inoue I, Goto S, Matsunaga $\mathrm{T}$ et al (2001) The ligands activators for peroxisome proliferator-activated receptor alpha (PPARalpha) and PPARgamma increase $\mathrm{Cu}^{2+}, \mathrm{Zn}^{2+}$-superoxide dismutase and decrease p22phox message expressions in primary endothelial cells. Metabolism 1:3-11

50. Evans M, Anderson RA, Graham J et al (2000) Ciprofibrate therapy improves endothelial function and reduces postprandial lipemia and oxidative stress in type 2 diabetes mellitus. Circulation 15:1773-1779

51. Diep QN, Amiri F, Touyz RM et al (2002) PPARalpha activator effects on Ang II-induced vascular oxidative stress and inflammation. Hypertension 6:866-871

52. Zhang H, Schmeisser A, Garlichs CD et al (1999) Angiotensin II-induced superoxide anion generation in human vascular endothelial cells: role of membrane-bound NADH-/NADPHoxidases. Cardiovasc Res 1:215-222

53. Grote K, Flach I, Luchtefeld M et al (2003) Mechanical stretch enhances mRNA expression and proenzyme release of matrix metalloproteinase-2 (MMP-2) via $\mathrm{NAD}(\mathrm{P}) \mathrm{H}$ oxidase-derived reactive oxygen species. Circ Res 11:e80-e86

54. Kim H, Haluzik M, Asghar Z et al (2003) Peroxisome proliferator-activated receptor-alpha agonist treatment in a transgenic model of type 2 diabetes reverses the lipotoxic state and improves glucose homeostasis. Diabetes 7:1770-1778

55. Guerre-Millo M, Gervois P, Raspe E et al (2000) Peroxisome proliferator-activated receptor alpha activators improve insulin sensitivity and reduce adiposity. J Biol Chem 22:16638-16642

56. Mussoni L, Mannucci L, Sirtori C et al (2000) Effects of gemfibrozil on insulin sensitivity and on haemostatic variables in hypertriglyceridemic patients. Atherosclerosis 2:397-406

57. Ide T, Tsunoda M, Mochizuki T, Murakami K (2004) Enhancement of insulin signaling through inhibition of tissue lipid accumulation by activation of peroxisome proliferator-activated receptor (PPAR) alpha in obese mice. Med Sci Monit 10: BR388-BR395 